\title{
THE DETERMINANTS OF INFANT, CHILD AND MATERNAL MORTALITY IN SUB-SAHARAN AFRICA
}

\author{
B M Imam and S F Koch*
}

\begin{abstract}
In Sub-Saharan Africa, infant, child and maternal mortalities are very high compared to other regions. We estimate a cross-country empirical model of the determinants of those mortalities. We find, similar to other studies, that in addition to per capita GDP, health and education interventions can affect mortalities, however, the effect depends on the mortality rate being modelled. Importantly, the prevalence of the adult HIVIAIDS infection rate is detrimentally impacting mortality in the Sub-Saharan region.
\end{abstract}

\section{Introduction}

During the past three decades the developing world has made enormous economic progress. According to the World Bank (1990), developing countries socioeconomic circumstances have been advancing much faster than today's developed countries did at a comparable stage, which can be seen most clearly in the rising trend for incomes and consumption: between 1965 and 1985 consumption per capita in the developing world grew by almost 70 percent. Broader measures of well-being confirm this picture; life expectancy, child mortality and educational attainment have all improved markedly. However, the report continues to say that 1 billion people are struggling to survive on less than $\$ 370$ a year ( $\$ 1$ a day). Furthermore, according to The Economist (2004), nearly 700 million Sub-Saharan Africans are living on $\$ 0,65$ per day.

In addition to struggling on low income, many people in Sub-Saharan Africa cannot attain adequate social services; they have poor access to health, education and other services. According to the millennium indicators (UNICEF/WHO, 2000), in 2000 $83 \%$ of urban and $45 \%$ of rural Sub-Saharan Africans were without sustainable access to clean water, while $74 \%$ of urban and $43 \%$ of rural Sub-Saharan Africans are without access to appropriate sanitation facilities. The lack of access to clean

\footnotetext{
* Respectively, Graduate Student and Associate Professor, Department of Economics, University of Pretoria, Pretoria, 0002, Republic of South Africa. The authors would like to thank the Government of Eritrea for funding the research efforts of Mr. Imam, and the authors would like to thank Walter de Wet for his comments concerning model specification. The authors would also like to thank an anonymous reviewer for their help. All other errors that might remain are the sole responsibility of the authors. This work is based, in part, on the analysis in Imam (2003).

Email: brhanums@yahoo.com and skoch@postino.up.ac.za
} 
facilities, as well as the surge in the prevalence of HIV/AIDS, might be able to explain the high mortality rates as well as short life expectancies in Sub-Saharan Africa. Research reported in this paper, will, however, focus on the mortality rates, rather than life expectancies. As of 1999, infant and child mortalities per thousand live births were 92 and 156 in Sub-Saharan Africa, respectively, while maternal mortality stood at 844 per 100,000 live births in the region (World Bank, 2002). Furthermore, medical care is an extremely scarce social service in many parts of Africa; for example, Todaro (2000) reveals that in 1995 the number of doctors per 100000 people averaged only 4,4 in the Sub-Sahara compared to 217 in developed nations.

Of more pressing recent concern is the HIV/AIDS pandemic. According to the most recent report by the World Health Organization (WHO) and the Joint United Nations Programme on HIV/AIDS (UNAIDS), between 34 and 46 million people are currently living with the HI virus; an estimated 2,5 million are children under the age of 15. Globally, it is estimated that 4,2 to 5,8 million are newly infected every year (approximately 3 million of those new infections occur in Sub-Saharan Africa), while 2,5 to 3,5 million died last year because of HIV/AIDS (UNAIDS/WHO, 2003).

Finally, education opportunities in the developing world often lag significantly behind those in the developed world. In spite of some quantitative advances in school enrolments, Sub-Saharan Africa is the region with the lowest average primary school completion rates, while literacy levels remain strikingly low compared with the developed nations. Harch (2002) found that the primary net enrolment ratio (the proportion of eligible school-age children who are enrolled, excluding those who are under-age or over-age) in Sub-Saharan Africa increased from $54 \%$ in 1990 to $60 \%$ in 1998 . Data from UNESCO (2000a) is a bit less encouraging, net enrolment increased from $54,5 \%$ in 1990 to $57,7 \%$ in 2000. Todaro (2000) suggests, unsurprisingly, that literacy in Sub-Saharan Africa averaged only $45 \%$ of the population, compared to $64 \%$ and $99 \%$ in other Third World and developed nations, respectively. However, once again, UNESCO (2000b) suggests that literacy rates are not as bad. In 2000, literacy rates in SubSaharan Africa averaged 76,4\%; for the entire developing world (including SubSaharan Africa) the average was $84,4 \%$, while the average in the developed world was $99,7 \%{ }^{1}$

As reported in this paper, these indicators of poor socioeconomic development (low incomes, poor access to basic health care services and low literacy rates) are purported to explain the overall poor levels of health as indicated by high levels of mortality for infants, children and mothers. Results are presented, beginning with Section 2, with the provision of a survey of the relevant literature to underpin the empirical models, which are explained in Section 3. The data is described in

\footnotetext{
${ }^{1}$ The differences in the UNESCO figures and those reported by Harch (2002) and Todaro (2000) are difficult to completely reconcile, although, clearly, the data sources are different. In particular, the UNESCO literacy data is only for ages 15 to 24 , while Todaro's data is for a larger segment of the population.
} 
Section 4, and the empirical results are examined in Section 5. Finally, conclusions and policy recommendations are discussed in Section 6.

\section{Review of relevant literature}

Not so long ago, development was conceived exclusively in terms of growth targets, with little regard to the beneficiaries of growth (Thirilwall, 1983). More recently, an emerging consensus has suggested that development should be measured by variables other than per capita GNP. Health variables (such as infant, child and maternal mortalities) and education indicators (such as literacy) should also be used to indicate a country's development status. The focus on non-income dimensions of development was promoted through the Basic Needs agenda in the 1970s, and the composite Physical Quality of Life Index (Todaro, 2000). Since 1990, the UNDP has strongly advocated a similar position in its Human Development Reports (HDRs), through the use of the Human Development Index. The International Development Targets, and the successor Millennium Development Goals, have also explicitly adopted a range of social goals as poverty reduction targets.

Hanmer et al. (1999) and Demery and Walton (1999) argue that earlier attempts to assess the determinants of mortality indicators were based on the premise that these indicators could be specified as functions of income growth alone. For example, McKeown (1976) argued that medical advances had little role in explaining mortality reductions in England since the eighteen-century. He argued that public health measures, such as the smallpox vaccination and the purification of milk played only a minor role in the reduction of mortality rates. The recent work of the World Bank reinforced this position by arguing that health spending is extremely ineffective in reducing mortality rates, which are mainly explained by a country's per capita income. Ravallion (1997), for example, admits that the relationship between social indicators and income per capita is imperfect, but he stressed that sustained improvements in welfare are best achieved through income increases. In addition, Filmer and Pritchet (1997) show that inter-country variation in infant and child mortalities is, primarily, explained by GNP per capita; the inclusion of health expenditure adds little explanatory power.

In contrast, the HDRs of the UNDP argue that achieving development requires looking beyond economic growth. For example, the mortality rate in Sri Lanka fell from 187 per 100000 in 1946 to 66 in 1947 to 21 by 1953, following a concerted malaria eradication campaign (Morduch, 1999). Economic growth alone could not have delivered these results so quickly. According to its 1996 HDRs (and the subsequent work in that vein by Ranis et al. (2000), the UNDP argued that whilst investing in human capital can lay the basis for subsequent growth, countries that have focused exclusively on economic growth have, in the end, achieved neither sustained growth nor human development. Similarly, Dr ze and Sen (1989) argue that waiting for the fruit of economic growth can take years and that public action can (and should) be directed at helping poor households do better today. They provide further evidence of the Sri Lanka success story: child mortality in Sri 
Lanka is 26 percent of what would be expected on the basis of average income alone, as a result of earlier direct health interventions.

\subsection{The determinants of infant and child mortalities}

The infant mortality is the number of deaths, occurring within one year of birth, per 1000 live births, while the child mortality rate refers to the annual number of children under the age of five, again, out of 1000 , who die during the year. Fortunately, deaths of infants and children have dropped rapidly over the last 25 years. In their Millennium Declaration, the United Nations (2000) showed that the number of child deaths fell from 15 million in 1980 (a rate of 204 per 1000$)^{2}$ to about 11 million in 1990 (a rate of 164 per 1000 ), and the improvement was the result of the spread of vaccination programs, oral re-hydration therapy, wider availability of antibiotics to treat pneumonia, and better social conditions.

Increases in income are usually associated with a higher degree of female participation in the labor force, which, in turn, reduces the demand for children because the opportunity cost of rearing children will be higher (Hojman, 1996). Gender inequality, too, matters in the reduction of the number of infant and child deaths. Waldman (1992) argues that unequal access for males and females to economic opportunities, education, health and other social services, especially professional attention preceding and during birth, adversely affects the health prospects of infants and children. Hojman (1996) explains that having professional attention at birth could reduce death risk, or at least help in identifying critical cases.

Maternal education also has a substantial impact on infant and child survival through increased awareness of problems and better feeding habits, among other reasons. Caldwell (1991) confirms that the mother's education is a robust determinant of infant and child survival in Bangladesh. Importantly, Kovsted, Pörtner and Tarp (2002), in a study in Guinea-Bissau, show that education is really only a proxy for actual health knowledge, the real determinant of child health and mortality. Based on household data from Sudan, Maglad (1993) revealed that parental education, income per adult and public health programs are significantly and negatively correlated with child mortality; maternal education, in particular, is found to have a larger significant effect than that of the father. Moreover, the years of schooling obtained by women reduces their birth rates, because better-educated women often marry, start families later and use better feeding practices (Okpala et al., 1996/97).

HIV/AIDS is also becoming a relatively recent challenge to child survival. It is responsible for an increase in infant and child deaths in several Sub-Saharan countries. In Uganda, both infant and child mortality rates increased in the1980s, probably because of the AIDS epidemic, and started declining in the early 1990s, a period when the epidemic was reported to be subsiding (Ntozi and Nakanaabi,

\footnotetext{
${ }^{2}$ Rate calculated from Children Data Bank

(http://childrendatabank.org/international/mortality/mortality1.html)

as an average across countries, rather than a population weighted average.
} 
1997). ${ }^{3}$ Although exact data for South Africa could not be located, data for other Sub-Saharan countries was located. In a UNAIDS/WHO (2002) report, the expected increase in child mortality was staggering. In Botswana and Zimbabwe, the number of child deaths was estimated to be 125 higher than it would have been without AIDS, while the figure for Kenya and Tanzania was approximately 50, and the figure for Malawi and Zambia was about $75 .^{4}$

Public interventions have also been shown to reduce infant and child death rates. Preston (1975) shows that low and declining infant and child mortalities from 1930 to 1960 can be attributed to the spread of anti-malaria programs. The study by Hanmer et al. (2003), which indicates that health, education and income per capita are important determinants of infant and child mortalities, provides evidence that interventions, especially immunizations, are, not only life saving, but are also cost effective. Alternatively, Hanmer and White (1999), who also identified per capita GDP, immunization rates, education, gender inequality as important determinants of child and infant mortality, find that the availability of health services, as measured by output variables (percentage of trained health attendant, proportion of nurses or doctors to population and etc.), rather than expenditure variables, are more robust determinants of infant and child mortality rates. Contrarily, Fayisa (2001) found that public expenditures do matter, as do per capita income and female literacy.

Although making use of the aforementioned insights and using more recent data, the research presented in this paper is directly related to Hanmer and Naschold's (2001) cross-sectional analysis of developing countries using 1990 data. They consider per capita GDP, education, access to health services and HIV/AIDS infection rates, immunization rates and education (the primary enrolment ratio acts as a proxy) as possible explanatory variables. They modelled infant and child mortalities as functions of per capita GDP, HIV/AIDS and physicians per thousand of population. Physician per thousand of population is a proxy for the availability of health services. Their regression findings suggest that while per capita GDP and the number of physicians per population are negatively correlated with infant and child deaths, the HIV/AIDS prevalence rate significantly aggravates these mortality rates. $^{5}$

\footnotetext{
${ }^{3}$ The result of the 1995 Uganda demographic survey shows that infant and child mortalities were declining in the 1990s. In 1995, infant and child mortalities per 1000 live births were reported at 81,3 and 147,3 , respectively. Five years before the survey, however, infant and child mortalities were 92 and 167,2

${ }^{4}$ Data was presented graphically in the report; therefore, the numbers are sight estimates from the graphs.

${ }^{5}$ Though the percentage of births attended by trained health personnel was assumed to have a significant impact, it could not be included in their estimation due to missing data. However, the primary school enrolment ratio was found to be insignificant and dropped from the model.
} 
Maternal mortality is defined as the number of deaths per 100000 live births. Maternal mortality in developing countries, at around 510000 a year, or about 99.4 percent of all maternal deaths in the world, is a major public health problem (Bulatao and Ross, 2001). Like infant and child mortality, maternal mortality is also affected by health, income, education, biological factors, and economic variables. In this context, access to health facilities and well-trained obstetric staff have been shown to play a significant role in improving maternal health.

Higher maternal mortality rates reflect weakness in the health care delivery system. Specifically, it reflects poor care during pregnancy, insufficiently trained staff and inadequate facilities (United Nations Millennium Declaration, 2000). The availability of a skilled birth attendant could help, through recognition, by preventing a medical crisis and providing life saving care when complications arise. Skilled birth attendants also provide mothers with basic information about care for themselves and their children before and after birth (United Nations Millennium Declaration, 2000).

Maternal mortality may also be affected by such factors as income and education, in addition to health aspects. For instance, if preventing maternal deaths requires relatively expensive hospital based intervention, national income may be crucial not only for its effect on public investment in medical supplies, but also because it allows for greater investment in such things as better transport systems and permits individuals to pay, more easily, for essential care or its components, such as needed drugs. Higher levels of education, on the other hand, could mean greater awareness of the risks of pregnancy and a better-informed approach to dealing with them (Hill et al., 2001)

The crude birth rate, too, has a substantial impact on maternal deaths. Since the maternal mortality ratio is a ratio of deaths to births, one might expect it to be unaffected by the number of births. However, if maternal survival depends on relatively scarce medical resources, a large number of births could aggravate any medical shortages. In addition, the lack of adequate spacing between pregnancies increases the risk to the mother, because she doesn't have time to recover from the extra physical demands made upon her by pregnancy and lactation. Females with birth spacing of less than one year face twice the risk of death compared to those with a longer interval (Labir, 2001). Thus, the higher the fertility rate, the larger the number of maternal deaths.

al-Meshari et al. (1996), in their study of a number of African countries, indicate that, compared to illiterates, educated females in Saudi Arabia bear fewer children and achieve lower rates of maternal mortality. In the Democratic Republic of Congo (then Zaire), the mortality rate for females with no education was 720 , compared to 130 for females with some education. The findings of Bulatao and Ross (2001), too, indicate that per capita income and the adequacy of access to maternal health services are important predictors of maternal mortality. They emphasized, among the services, those involving emergency treatment and 
avoidance of births (abortion and family planning) have a stronger relationship with maternal death than those involving prevention (antenatal care) and risk identification (general delivery care). Therefore, improvement in health services is beneficial for lowering maternal mortality. In a related study by Hanmer and Naschold (2001), the percentage of births attended by trained personnel, the adult literacy rate and the adult HIV/AIDS infection rate are significant determinants of maternal mortality. However, the level of per capita GDP is found to have little influence on maternal health once the effects of HIV/AIDS, access to health services and adult literacy are included in the analysis. Finally, the study by Goodburn and Campbell (2001) revealed that some developing countries, such as China, Sri Lanka, and Malaysia, have reduced maternal mortality rates after improving the coverage and quality of their health services.

\section{The data}

The analysis presented in this paper makes extensive use of secondary sources of data for the year 1999. Most of the relevant Sub-Saharan African data that are used for regression analysis are derived from the World Bank (African Development Indicators of 2002 and 2003). The year 1999 is chosen because it is the latest data available and, indeed, complete data on most relevant variables are found in this period. ${ }^{6}$

The data considered are infant mortality (IMR), child mortality (CMR), maternal mortality (MMR), population statistics, real GDP per capita, population per physician (LN_PPP), percent of births attended by trained health personnel (LN_PBA_TP), adult HIV/AIDS infection rate (LN_AAIR), immunization rate against DPT (LN_IMU), female literacy (LN_F_LIT), female labor force participation (LN_PWLF) and war (DUM_WAR) for 38 Sub-Saharan African countries. ${ }^{7}$ Real GDP is measured in $\$ \mathrm{USS}^{-}$million. ${ }^{8}$ Although there are more countries in Sub-Saharan Africa and there may be a difference between Africa and other parts of the world, the analysis will be limited to the Sub-Saharan African countries for which complete data is available; furthermore, no attempt will be made to generalize the results beyond Sub-Saharan Africa. ${ }^{9}$

For the purpose of comparison, separate mean and standard deviation values of mortality indicators, in conjunction with their possible determinant variables, are calculated for the entire Sub-Saharan region and for each sub-region as shown in

\footnotetext{
${ }^{6}$ Some possible explanatory variables are excluded from the model on account of missing data.

${ }^{7}$ The countries and regions are listed in the footnote to Table 1.

${ }^{8}$ The war dummy is equal to one if the sample country was directly or indirectly engaged in war during the last decade (1989 to 1999), otherwise it is zero.

${ }^{9}$ Unfortunately, the completeness and accuracy of the available data cannot be verified. Clearly, if all of the variables are measured with error, then there is little that can be done to improve the quality of the estimates, other than wait for better data in the future.
} 
Table $1 .{ }^{10}$ A comparison of the three sub-regions indicates that Southern African countries outperformed the other two sub-regions. Clearly, for the period of study, Southern African countries accounted for the lowest average infant, child and maternal mortality rates, although there is more variability. Conversely, a critical glance of the average rates of the indicators shows that, except in the case of maternal mortality and women's labour force participation, East and Central Africa sub-regions were below the other two sub-regions. Decades of internal and external war between countries of the sub-region might have contributed to the poor performance within this sub-region.

Table 1: Mean and Standard deviation of Sub-Saharan Africa and its three Sub-regions

\begin{tabular}{l|c|c|c|c}
\hline & $\begin{array}{c}\text { East and Central } \\
\text { Africa }\end{array}$ & $\begin{array}{c}\text { Western } \\
\text { Africa }\end{array}$ & $\begin{array}{c}\text { Southern } \\
\text { Africa }\end{array}$ & $\begin{array}{c}\text { Sub-Saharan } \\
\text { Africa }\end{array}$ \\
\hline IMR & 93,55 & 91,56 & 79,11 & 89,18 \\
& $(19,39)$ & $(18,95)$ & $(35,54)$ & $(23,93)$ \\
\hline CMR & 156,18 & 162,89 & 128,33 & 152,76 \\
& $(33,30)$ & $(39,55)$ & $(62,44)$ & $(45,38)$ \\
\hline MMR & 886,09 & 719,11 & 576,44 & 733,66 \\
& $(362,02)$ & $(202,79)$ & $(425,55)$ & $(315,91)$ \\
\hline LN_GDP_CAP & 5,47 & 6,12 & 6,66 & 6,06 \\
& $(0,41)$ & $(0,84)$ & $(1,19)$ & $(0,93)$ \\
\hline LN_AAIR & 1,97 & 1,06 & 1,09 & 1,33 \\
& $(0,90)$ & $(0,87)$ & $(2,64)$ & $(1,50)$ \\
\hline LN_IMU & 4,16 & 3,66 & 4,15 & 3,92 \\
& $(0,32)$ & $(0,69)$ & $(0,44)$ & $(0,59)$ \\
\hline LN_PBA_TP & 3,28 & 3,63 & 4,04 & 3,63 \\
& $(0,90)$ & $(0,62)$ & $(0,54)$ & $(0,73)$ \\
\hline LN_PPP & 10,13 & 9,53 & 8,89 & 9,55 \\
& $(0,50)$ & $(0,77)$ & $(1,34)$ & $(0,97)$ \\
\hline LN_PWLF & 3,80 & 3,75 & 3,74 & 3,76 \\
& $(0,15)$ & $(0,11)$ & $(0,13)$ & $(0,13)$ \\
\hline LN_F_LIT & 3,82 & 2,88 & 3,52 & 3,30 \\
& $(0,38)$ & $(1,98)$ & $(2,20)$ & $(1,75)$ \\
\hline DUM_WAR & 0,73 & 0,22 & 0,33 & 0,39 \\
& $(0,47)$ & $(0,43)$ & $(0,50)$ & $(0,50)$ \\
\hline NOt? & & $E a s t$ & and & \\
\hline
\end{tabular}

Note: Standard deviation in parentheses. East and Central Africa: Burundi, Central Africa Republic, Chad, Eritrea, Ethiopia, Kenya, Rwanda, Sudan, Tanzania, Uganda, and Zambia. West Africa: Benin, Burkina Faso, Cameroon, Democratic Republic of Congo, Congo, Cote d'Ivoire, Equatorial Guinea, Gabon, Gambia, Ghana, Guinea, Guinea-Bissau, Mali, Mauritania, Niger, Nigeria, Senegal and Togo. Southern Africa: Angola, Botswana, Comoros, Lesotho, Madagascar, Malawi, Mauritius, Namibia, and Zimbabwe.

\footnotetext{
${ }^{10}$ Although the data is presented by sub-region in the table, regional dummy variables, used in the initial specifications of the model, had negligible explanatory power and were removed from the empirical models.
} 


\section{Estimation methods and regression results}

Three separate equations are estimated for: Infant Mortality Rates, Child Mortality Rates, and Maternal Mortality Rates. The empirical models of infant, child and maternal mortalities are developed on the basis of the previous empirical studies, primarily on the Hanmer and White (1999) identification of robust determinants of infant and child mortalities. The functional forms are, however, adopted directly from Hanmer and Naschold (2001) with minor adjustments. In this regard, the following independent variables are included in the model specifications: health care (percentage of births attended by trained health personnel, population per physician, immunization against DPT), adult HIV/AIDS prevalence, per capita GDP, female literacy rates, female labour force participation rates, and war participation.

Health variables, such as the percentage of births attended by trained health personnel, number of physicians per capita, and the immunization rate against DPT indicate the quality and availability of health services that could possibly reduce mortality rates. Female literacy is hypothesized to reduce mortality rates because better-educated women have lower costs of information acquisition, and can, therefore, access better care for themselves and their children. Female participation in the labour force may reduce mortality rates as well, since it is a proxy for bargaining power within the household. However, higher labour force participation may also raise a mother's opportunity cost of time, thereby reducing the quality of care, and, thus, raising the mortality rate. Furthermore, in some countries of SubSaharan Africa, infant and child mortalities have begun to increase after years of steady improvement, because of the HIV/AIDS epidemic (Hanmer and White, 1999); therefore, a measure of the epidemic is included in the model. Finally, a war dummy is included in the model to capture its destructive influence in Africa. It is possible that participation in war is highly correlated with other right hand side variables, especially health care delivery and services. However, in regressions excluding war participation, available from the authors, the results were similar to the ones reported below, and, therefore, multi-collinearity is not likely to be a problem.

\subsection{Estimation methods for infant and child mortality models}

The models for infant and child mortalities are similar, except for the dependent variables. The independent variables used for estimation of these mortality indicators are: GDP per capita, adult HIV/AIDS infection rate, health care, immunization rate against DPT, female labour force participation, the female literacy rate and the prevalence of war. Specifically, Sub-Saharan Africa's infant and child mortality rates are modelled, with the expected signs, as ${ }^{11}$ :

\footnotetext{
${ }^{11}$ Where $\mathrm{i}=1,2,3, \ldots .38$ (countries in the sample are listed at the bottom of Table 1). * HEALTHCARE is proxied by PBA_TP and PPP in IMR and CMR, respectively.
} 


$$
\begin{aligned}
& \mathrm{IMR}_{\mathrm{i}} / \mathrm{CMR}_{\mathrm{i}}=\mathrm{a}_{0}-\mathrm{a}_{1} \mathrm{LN} \_\mathrm{GDP} \_\mathrm{CAP}_{\mathrm{i}}+\mathrm{a}_{2} \mathrm{LN} \_\mathrm{AAIR}_{\mathrm{i}}-\mathrm{a}_{3} \mathrm{LN} \_\operatorname{HEALTHCARE}_{\mathrm{i}}^{*} \\
& -\mathrm{a}_{4} \mathrm{LN} \mathrm{IMU}_{\mathrm{i}} \pm \mathrm{a}_{5} \mathrm{LN} \mathrm{WWWLF}_{\mathrm{i}}-\mathrm{a}_{6} \mathrm{LN} \mathrm{WN}_{-} \mathrm{LIT}_{\mathrm{i}}+\mathrm{a}_{7} \mathrm{DUM} \mathrm{WAR}_{\mathrm{i}}+\varepsilon_{\mathrm{i}}
\end{aligned}
$$

Since our observations are cross sectional, using data for the year 1999, heteroskedasticity of unknown form could be encountered. The White (1980) heteroskedasticity-consistent covariance estimator will, thus, be used. ${ }^{12}$ A JarqueBera (1981) normality test is used to determine whether or not the error terms $\left(\varepsilon_{\mathrm{i}}\right)$ are normally distributed. ${ }^{13}$ Furthermore, model specification bias is tested through a Ramsey (1969) reset test. ${ }^{14}$

\subsection{Estimation method for maternal mortality model}

Maternal mortality, on the other hand, is modelled as a function of GDP per capita, health care (the percentage of births attended by trained health personnel acts as a proxy for health care availability), adult HIV/AIDS infection rate, female literacy rate and the prevalence of war. The following maternal mortality model, with the expected signs, is estimated for Sub-Saharan Africa. ${ }^{15}$

$$
\begin{aligned}
& \mathrm{MMR}_{\mathrm{i}}=\mathrm{b}_{0}-\mathrm{b}_{1} \mathrm{LN} \_\mathrm{GDP} \_\mathrm{CAP}_{\mathrm{i}}+\mathrm{b}_{2} \mathrm{LN}_{-} \mathrm{AAIR}_{\mathrm{i}}-\mathrm{b}_{3} \mathrm{LN} \_ \text {HEALTHCARE } \mathrm{i}_{\mathrm{i}}^{*} \pm \mathrm{b}_{4} \mathrm{LN} \_ \text {WPWLF } \\
& -b_{5} \mathrm{LN}_{-} \mathrm{F}_{-} \mathrm{LIT}_{\mathrm{i}}+\mathrm{b}_{6} \mathrm{DUM} \mathrm{WAR}_{\mathrm{i}}+\varepsilon_{\mathrm{i}}
\end{aligned}
$$

Analogous to the infant and child mortality models, the White (1980) heteroskedasticity-consistent covariance estimator will be used. Likewise, the Jarque-Bera (1981) normality test and the Ramsey (1969) reset model specification bias test are conducted to detect any violations of the primary OLS assumptions.

\footnotetext{
${ }^{12}$ The problem of heteroskedasticity is more common in cross-sectional data. The presence of heteroskedasticity in the disturbance of an otherwise specified model leads to consistent but inefficient parameter estimates. This lack of efficiency makes the usual hypothesis testing procedures dubious. A heteroskedasticity-consistent covariance matrix estimator, therefore, provides correct estimates of the coefficient covariances in the presence of heteroskedasticity of unknown form

${ }^{13}$ Jarque-Bera is a test statistic for testing whether a data series is normally distributed. Under the null hypothesis of a normal distribution, the Jarque-Bera statistic is distributed as chi-square with 2 degrees of freedom. If the $p$ value of the computed chi-square in an application is sufficiently low, one can reject the hypotheses that the residuals are normally distributed; otherwise the normality assumption couldn't be rejected.

${ }^{14}$ Reset stands for Regression Specification Error Test and was proposed by Ramsey (1969). Reset is a general test for the following types of specification errors: Omitted variables, incorrect functional form and correlation between the independent variables and the error terms. Under such specification errors, OLS estimators will be biased and inconsistent, and conventional inferences procedures will be invalidated. The null hypothesis in Reset test is that the model is correctly specified.

${ }^{15}$ Where $\mathrm{i}=1,2,3, \ldots .38$ (countries in the sample are listed at the bottom of Table 1). * HEALTHCARE is proxied by PBA_TP.
} 


\section{Results}

\subsection{Infant mortality regression results}

The regression results show that all explanatory variables, with the exception of female participation in the labour force and the war dummy, are significant and with the expected signs. As can be seen in Table 2, higher levels of per capita GDP, female literacy and immunization rates, and greater availability of health care services significantly reduce the infant mortality rate in the Sub-Saharan region. Conversely, a higher adult HIV/AIDS prevalence rate leads to more infant deaths in the region. Table 2 presents results from numerous specifications, which were used to examine the robustness of the results.

Table 2: Infant mortality regression results

(Dependent variables: IMR)

\begin{tabular}{|c|c|c|c|c|}
\hline Variables & Eq. 1 & Eq. 2 & Eq. 3 & Eq. 4 \\
\hline Constant & $\begin{array}{r}172,63 * \\
(6,63) \\
\end{array}$ & $\begin{array}{c}189,96^{*} \\
(7,86) \\
\end{array}$ & $\begin{array}{l}-69,36 \\
(-0,47) \\
\end{array}$ & $\begin{array}{r}247 * * \\
(2,33) \\
\end{array}$ \\
\hline LN_GDP_CAP & $\begin{array}{c}-13,30 * \\
(-3,09)\end{array}$ & & & $\begin{array}{c}-9,89^{*} \\
(-2,96)\end{array}$ \\
\hline$\overline{\text { DUM_WAR }}$ & $\begin{array}{c}-7,31 \\
(-1,05)\end{array}$ & & & $\begin{array}{l}-11,66^{* * *} \\
(-1,98)\end{array}$ \\
\hline LN_PBA_TP & & $\begin{array}{c}-14,42^{*} \\
(-3,29) \\
\end{array}$ & & $\begin{array}{c}-10,73^{* *} \\
(-2,16)\end{array}$ \\
\hline LN_IMU & & $\begin{array}{c}-14,11^{*} \\
(-3,02)\end{array}$ & & $\begin{array}{l}-8,94^{* *} \\
(-2,15)\end{array}$ \\
\hline LN_AAIR & & $\begin{array}{l}5,13^{* *} \\
(2,22)\end{array}$ & & $\begin{array}{r}5,36^{*} \\
(2,94)\end{array}$ \\
\hline LN_PWLF & & & $\begin{array}{l}44,90 \\
(1,16)\end{array}$ & $\begin{array}{c}-3,92 \\
(-0,15) \\
\end{array}$ \\
\hline LN_F_LIT & & & $\begin{array}{c}-3,13 \\
(-1,57)\end{array}$ & $\begin{array}{c}-3,56^{*} \\
(-2,58)\end{array}$ \\
\hline Adjusted $\mathrm{R}^{2}$ & 0,21 & 0,36 & 0,08 & 0,47 \\
\hline $\mathrm{n}$ & 38 & 38 & 38 & 38 \\
\hline
\end{tabular}

The model performs well for a cross sectional study, as $47 \%$ of the variation is explained by the variables in the model. The F-statistic confirms that the entire model is significant at the $1 \%$ confidence level. The Jarque-Bera normality test and the Ramsey reset test indicate the presence of a normal distribution in the error terms and the absence of model specification bias, respectively.

Because these equations are log-linear, the coefficients represent proportions, however, the proportional relation is such that the change in the left hand side is given by the coefficient times the percent change in the right hand side. In other words, a $1 \%$ increase in the per capita GDP (measured in natural $\log$ ) will lead to 
approximately 10 fewer infant mortalities per 1000 live births; a 1\% increase in the proportion of births attended, a 1,2\% increase in the rate of immunizations, or a $2 \%$ decrease in the HIV/AIDS infection rate would lead to a similar reduction in the infant mortality by 10 (per 1000 live births). Given the low base of per capita income and birth attendance, these percentage changes are achievable.

\subsection{Child mortality regression results}

Table 3 shows the results for a number of specifications for determinants of child mortality. All variables, except the population per physician, female participation in the labour force, and the war dummy, have the expected signs. Per capita GDP, female literacy, the immunization rate and the prevalence rate of HIV/AIDS infection have significant detrimental effects on child mortality in Sub-Saharan Africa. Unlike the case of infant mortality, the role of health care services (where population per physician is the proxy) is insignificant.

\section{Table 3: Child mortality regression results}

\begin{tabular}{|c|c|c|c|c|}
\hline Variables & Eq. 1 & Eq. 2 & Eq. 3 & Eq. 4 \\
\hline Constant & $\begin{array}{r}322,50^{*} \\
(6,67) \\
\end{array}$ & $\begin{array}{c}142,04 * * \\
(2,00) \\
\end{array}$ & $\begin{array}{r}-171,37 \\
(-0,68) \\
\end{array}$ & $\begin{array}{c}460,01 * * \\
(2,52) \\
\end{array}$ \\
\hline LN_GDP_CAP & $\begin{array}{c}-27,04^{*} \\
(-3.52) \\
\end{array}$ & & & $\begin{array}{c}-27,69^{*} \\
(-4,65) \\
\end{array}$ \\
\hline DUM_WAR & $\begin{array}{l}-14,94 \\
(-1,14) \\
\end{array}$ & & & $\begin{array}{l}-18,39 * * * \\
(-1,67)\end{array}$ \\
\hline$\overline{\text { LN_IMU }}$ & & $\begin{array}{l}-36,14^{*} \\
(-4,04) \\
\end{array}$ & & $\begin{array}{c}-20,42 * * \\
(-2,40) \\
\end{array}$ \\
\hline LN_PPP & & $\begin{array}{l}15,25^{* * * *} \\
(1,93)\end{array}$ & & $\begin{array}{c}-2,26 \\
(-0,34) \\
\end{array}$ \\
\hline LN_AAIR & $\begin{array}{c}5,08 \\
(1,06) \\
\end{array}$ & & & $\begin{array}{l}9,48^{* *} \\
(2,41)\end{array}$ \\
\hline LN_PWLF & & & $\begin{array}{l}91,07 \\
(1,38) \\
\end{array}$ & $\begin{array}{c}-4,71 \\
(-0,11) \\
\end{array}$ \\
\hline LN_F_LIT & & & $\begin{array}{c}-5,57 \\
(-1,47) \\
\end{array}$ & $\begin{array}{l}-7,71^{*} \\
(-3,22) \\
\end{array}$ \\
\hline Adjusted $\mathrm{R}^{2}$ & 0,25 & 0,30 & 0,08 & 0,44 \\
\hline $\mathrm{n}$ & 38 & 38 & 38 & 38 \\
\hline
\end{tabular}

While increases in the level of GDP per capita, female literacy and the spread of immunization significantly reduce the likelihood of child death, a rise in the adult AIDS infection rate aggravates child mortality, considerably. This model, which explains $44 \%$ of the variation on dependent variable, is significant at the $1 \%$ confidence level. The Jarque-Bera normality test indicates that the error terms are normally distributed, and there is no model specification bias revealed by the Ramsey reset test. 
Child mortality estimates are, generally, more responsive than the infant mortality estimates. For example, a one-third percent increase in (logged) Real GDP per capita can reduce child mortality by 10 deaths, per 1000 children aged between one and five. A similar 10-death reduction is estimated to occur if the (logged) immunization rate were to increase by one-half percent, if the (logged) HIV/AIDS infection rate were reduced by $1 \%$, or if (logged) female rates of literacy were to increase by $1,3 \%$. Again, these are achievable changes.

\subsection{Maternal mortality regression results}

Table 4 depicts the regression results of a number of maternal mortality specifications. As it is shown in the table, the signs of all the coefficients of the independent variables correspond to our expectations. However, only per capita GDP, health care service (the percentage of births attended by trained health personnel is a proxy) and the war dummy have a significant impact on maternal mortality. Thus, a rise in per capita GDP and an improvement in basic health care services have significantly reduced maternal mortality in Sub-Saharan region. The prevalence of war, however, is associated with higher maternal deaths in the region. The entire model is significant at the one percent confidence level, while $54 \%$ of variation is explained by the specification.

Table 4: Maternal mortality regression results

(Dependent variable: MMR)

\begin{tabular}{lcccc}
\hline VARIABLES & Eq. 1 & Eq. 2 & Eq. 3 & Eq. 4 \\
\hline \multirow{2}{*}{ CONSTANT } & $1502,99^{*}$ & $1668,27^{*}$ & $-519,31$ & 1956,28 \\
& $(5,78)$ & $(6,72)$ & $(-0,35)$ & $(1,64)$ \\
\hline LN_GDP_CAP & $-143,92^{*}$ & & & $-108,84^{*}$ \\
& $(-3,58)$ & & $(-3,47)$ \\
\hline DUM_WAR & $259,88^{*}$ & & $227,09^{*}$ \\
& $(2,82)$ & & & $(2,82)$ \\
\hline LN_PBA_TP & & $-263,56^{*}$ & $-156,37^{*}$ \\
& & $(-4,23)$ & & $(-4,85)$ \\
\hline LN_AAIR & 15,89 & & 6,67 \\
& & $(0,53)$ & & $(0,33)$ \\
\hline LN_PWLF & & 357,75 & 10,66 \\
& & & $(0,93)$ & $(0,04)$ \\
\hline LN_F_LIT & & $-28,05$ & $-40,82$ \\
& & 0,34 & $-0,64)$ & $(-1,57)$ \\
\hline Adjusted R & & 38 & $-0,00$ & 0,54 \\
\hline N & 0,40 & -58 & 38
\end{tabular}

All independent variables are in log form. t-statistic in parentheses. * Significance level at 1\%; ** significance level at $5 \%$; *** significance level at $10 \% ; \mathrm{n}$ is the sample size.

Statistically, the model is correctly specified and the error terms are normally distributed, confirmed from the Ramsey reset test and the Jarque-Bera test, respectively.

Maternal mortality is, generally, less responsive than either infant mortality, or child mortality, due to the fact that maternal mortalities are per 100000 rather than 
per 1000 . For example, reducing maternal deaths (per 100000 births) by 1000 would require a $9,3 \%$ increase in (logged) real per capita income or a $6,4 \%$ increase in the (logged) proportion of births attended by medical professionals. ${ }^{16}$

\section{Conclusions and policy implications}

\subsection{Conclusions}

Several studies show that, in addition to income, health and education factors have a substantial impact on the improvement of infant, child and maternal mortalities. Most of the studies demonstrate that, whilst income is needed to sustain the expansion of quality education and health to the society, specific health and education interventions can significantly affect the preceding mortality indicators. The results presented in this paper reinforce this position by providing evidence that particular health aspects are robust determinants of the aforementioned human development indicators in Sub-Saharan Africa. The findings suggest that reductions in infant, child and maternal mortalities are mainly conditional on health and educational interventions as well as per capita income in Sub-Saharan Africa.

A quick review of the infant mortality regression results, for example, indicate that per capita GDP, health care services (proxied by the percentage of births attended by trained health personnel), the immunization rate, adult AIDS prevalence rate and the female literacy rate are major determinants. Of all the independent variables, per capita GDP, female literacy and the prevalence of adult HIV/AIDS are most highly correlated with infant mortality in the Sub-Saharan region. Surprisingly, however, female participation in the labour force is not significantly related to infant mortality in the region.

Similarly, child mortality has a strong correlation with per capita GDP, the prevalence of adult HIV/AIDS infection, the immunization rate, and the level of female literacy. Particularly, per capita GDP and female literacy are highly negative and significant. However, health care services (proxied by population per physician) and female participation in the labour force aren't significantly related to the level of child mortality in Sub-Saharan Africa.

From the regression result of maternal mortality, only GDP per capita, health care service (proxied by percentage of births attended by trained health personnel) and the prevalence of war are significant correlates of maternal mortality in SubSaharan Africa. Female literacy and female participation in the labour force are not significantly related to maternal mortality in the region. Unlike the case of infant and child mortality, the spread of AIDS in the adult population has not, yet, had an influence on maternal deaths.

\footnotetext{
${ }^{16}$ Due to the 100000 denominator in maternal mortality, a reduction of 1000 maternal deaths is a reduction in deaths of 10 per 1000, which was the base used for the infant and child mortality results discussion, above. The maximum maternal death rate used in the analysis was only 1500 , and, therefore, a reduction, by 1000 , in maternal deaths would be an unlikely prospect.
} 
Reductions in infant, child and maternal mortalities in the Sub-Saharan region are conditioned on health and education factors in addition to per capita income. Hence, there are good prospects to improve these human development indicators as long as appropriate policies are in place to support the gains that higher income levels can bring. Therefore, in policy terms, some recommendations can be made.

A large improvement in the health of the population can be achieved if there is a broad and long-lasting commitment to improving the delivery of basic health care services and education. Thus, in order to reduce infant, child and maternal mortality rates in Sub-Saharan countries, the governments of this region should focus on increasing their public spending to improve the capacity of their countries' health and education sectors. To reduce infant and child deaths, effort should be exerted to increase the spread of immunization coverage and concomitant control of the spread of the HIV/AIDS epidemic in the region. Educational opportunities for women should also be expanded to help reduce infant and child deaths in SubSaharan Africa. Furthermore, mother's access to trained birth attendants should be improved in order to save the lives of infants and mothers in the region. Finally, several countries in Sub-Saharan Africa are directly or indirectly engaged in war; therefore, resolving their internal as well as their external conflicts through peaceful means could help shift resources to the protection of maternal health, or, more likely, increase the resources available for policies to enhance female literacy and provide primary care for pregnant women and their new offspring.

\section{References}

al-Meshari, A, Chattopadhyay, S K, Yunes, B and Hassonah, M (1996): "Trends in maternal mortality in Saudi Arabia", International Journal of Gynaecology and Obstetrics: the Official Organ of the International Federatiuon of Gynaecology and Obstetrics, 52, 25-32.

Bera, A and Jarque, C M (1981): "Efficient Tests for Normality, Heteroskedasticity, and Serial Independence of Regression Residuals: Monte Carlo Evidence", Economic Letters, 7, 313-318.

Bulatao, R A and Ross, J A (2001): “Do Health Services Reduce Maternal Mortality?”, Evidence from ratings of maternal programs, measure evaluation project.

http://www.cpc.unc.edu/measure/publications/workingpapers/wp0139.pdf

Caldwell, J C (1991): "The Soft Underbelly of Development: Demographic Transition in Conditions of Limited Economic Change, Comments", Proceedings of the World Bank Annual Conference on Development Economics, 207-253.

Demery, L and Walton, M (1999): “Are Poverty and Social Goals for the $21^{\text {st }}$ Century Attainable?", Paper presented at "What can be done about poverty?", Institute for Development Studies, Sussex.

Dr ze, J and Sen A (1989): Hunger and Public Action, Clarendon Press, Oxford.

Fayissa, B (2001): "The Determinants of Infant and Child Mortality in Developing Countries: The Case of Sub-Saharan Africa", The Review of Black Political Economy 29(2), 83-100.

Filmer, D and Pritchet, L (1997): "Child Mortality and Public Spending on Health: How Much Does Money Matter?”, Policy Research Working Paper 1864, Washington, DC. 
Goodburn, E and Campbell, D (2001): "Reducing Maternal Mortality in the Developing World: Sector Wide Approach May be the Key", Center for Sexual and Reproductive Health, 3, John Snow International, London.

Hanmer, L, Lensink, R and White, H (2003): "Infant and Child Mortality in Developing Countries: Analyzing the Data for Robust Determinants", Journal of Development Studies, 40(1), 101-118.

Hanmer, L and Naschold, F (2001): “Attaining the International Development Targets: Will Growth be Enough?", WIDER Development Conference on Growth and Poverty.

Hanmer, L and White, H (1999): "The Impact of HIV/AIDS on Under Five Mortality in Zambia and Zimbabwe", in Human Development in Sub-Saharan Africa: The Determinants of Under Five Mortalities, ISSAS: The Hague, Journal.

Hanmer, L, Pyatt, G and White, H (1999): “What do the World Bank's Poverty Assessments Teach us about Poverty in Sub-Saharan Africa?", Development and Change, 30(4), 795-823.

Harch, E (2002): "Education in Africa", African Recovery Special Report, United Nations, 14(2). www.un.org/ecoscdev/geninfo/afrec/vol14no2/educat.htm

Hill, K, Abouzhar, C and Wardlaw, T (2001): "Estimates of Maternal Mortality for 1995”, Bulletin of WHO, 79(3), 182-193.

Hojman, D E (1996): "Economic and Other Determinants of Infant and Child Mortality in Small Developing Countries: The case of Central America and the Caribbean", Department of Economics and Institute of Latin America Studies, University of Liverpool, Chapman and Hall, UK.

Imam, B M (2003): The Determinants of Infant, Child, and Maternal Mortality in Sub-Saharan Africa, University of Pretoria, Masters in Commerce Essay, 58pp.

Kovsted, J, Pörtner, C C and Tarp, F (2002): "Child Health and Mortality: Does Health Knowledge Really Matter?”, Journal of African Economies, 11(4), 542-560.

Labir, I (2001): "Maternal Mortality: Challenges and Strategies", Seva-Mandir: Newsletter, April-June. www.sevamandir.org/news_letter/pages10_maternal.htm

Maglad, N A (1993): "Socioeconomic Determinants of Fertility and Child Mortality in Sudan", Yale Economic Growth Center Discussion Paper 686.

McKeown, T (1976): The Modern Rise of Population, Academic Press, New York.

Morduch, J (1999): Reforming Poverty Alleviation Policies, Center for Research on Economic Development and Policy Reform, Stanford University.

Ntozi, J P M, and Nakanaabi, I M (1997): The AIDS Epidemic and Infant and Child Mortality in Six Districts of Uganda, Department of Population Studies, Institute of Statistics and Applied Economics, Makerere University, Health Transition Review, 7, Kampala.

Okpala, A O, Felix, O and Pender, G (1996/1997): "Poverty and Child Survival Rates in Sub-Saharan Africa”, Journal of Applied Business Research, 13(1), 1-8.

Preston, S (1975): "The Changing Relation Between Mortality Levels and Economic Development", Population Studies 29(2), 231-248.

Ranis, G, Stewart, F and Ramirez, A (2000): "Economic Growth and Human Development", World Development, 28(2), 197-219.

Ramsey, J (1969): “Tests for Specification Errors in Classical Linear Least Squares Regression Analysis", Journal of the Royal Statistical Society, Series B, 31, 350-370. 
Ravallion, M (1997): Good and Bad Growth: The Human Development Report, World Development Report.

The Economist (2004): "First get the basics right", How to make Africa smile: A survey of SubSaharan Africa. The Economist 370(8358), January 17.

Thirilwall, A P (1983): Growth and Development, Third Edition, The Macmillan Press LTD, Hong Kong.

Todaro, M (1994): Economic Development, Fifth Edition, Addison Wesley, New York.

Todaro, M (2000): Economic Development, Seventh Edition, Addison Wesley, New York.

United Nations Children's Fund and the World Health Organization (UNICEF/WHO) (2000): "Water, percentage of population with access to improved drinking water sources, total",

http://milleniumindicators.un.org/unsd/mi/mi_indicator_xrxx.asp?ind_code $=30$.

United Nations Children's Fund and the World Health Organization (UNICEF/WHO) (2000): "Sanitation, percentage of population with access to improved sanitation, total", http://milleniumindicators.un.org/unsd/mi/mi_indicator_xrxx.asp?ind_code $=31$.

United Nations Educational, Scientific and Cultural Organization (UNESCO) (2000a): "Net enrolment in primary education",

http://milleniumindicators.un.org/unsd/mi/mi_indicator_xrxx.asp?ind_code $=6$.

United Nations Educational, Scientific and Cultural Organization (UNESCO) (2000b): "Literacy rate of 15-24 year olds",

http://milleniumindicators.un.org/unsd/mi/mi_indicator_xrxx.asp?ind_code $=8$.

United Nations, Joint Programme on HIV/AIDS and The World Health Organization (UNAIDS/WHO) (2002): "HIV/AIDS in sub-Saharan Africa: A Powerpoint Presentation", http://www.who.int/hiv/facts/ppt1/en/.

United Nations, Joint Programme on HIV/AIDS and The World Health Organization (UNAIDS/WHO) (2003): AIDS epidemic update: December 2003, UNAIDS, Geneva, Switzerland.

United Nations Millennium Declaration (2000): "Millennium Development Goals", The World Bank. www.devtgoals.org/

Waldmann, R J (1992): “Income Distribution and Infant Mortality", Quarterly Journal of Economics, 107(4), 1283-1302.

White, H (1980): “A Heteroskedasticity-Consistent Covariance Matrix Estimator and a Direct Test for Heteroskedasticity”, Econometrica, 48, 817-838.

World Bank (1980): World Development Report 1980, Oxford University Press, New York.

World Bank (1990): World Development Report 1990, Oxford University Press, New York.

World Bank (2002): African Development Indicators 2002, Oxford University Press, New York.

\section{Appendix: Data sources}

World Bank (2002): African Development Indicators 2002, Oxford University Press, New York.

World Bank (2003): African Development Indicators 2003, Oxford University Press, New York. 
